\title{
Una defensa de la «prioridad ontológica de lo social»: epistemología e ideología en el modelo nuclear de la herencia $y$ en el origen de la biología molecular
}

\section{Defending the Ontological Priority of the Social: Epistemology and Ideology in the Nuclear Model of Inheritance and in the Beginning of the Molecular Biology}

\author{
NALLIELY HERNÁNDEZ \\ Universidad de Gudalajara, México
}

Recibido:10/04/2017 Aceptado:21/09/2016

\section{RESUMEN}

En este artículo vincularé algunos factores epistémicos y sociales que jugaron un papel relevante en el desarrollo del modelo conceptual del gen predominante durante las décadas iniciales de la biología molecular. Tomaré como referencia principal la relación con la física como disciplina que influyó en su gestación, tanto en la configuración de sus supuestos ontológicos y epistemológicos como en la aportación de nuevas metodologías, y que transfiere a la biología un modelo de objetividad gestado a partir de la tradición moderna. Interpretaré esta relación entre lo epistémico y lo social con ayuda de algunas tesis pragmatistas para defender lo que Rorty denominó «la prioridad ontológica de lo social» que implica pensar a la ciencia como parte de una política cultural.

$$
\text { PALABRAS-CLAVE: }
$$

BIOLOGÍA MOLECULAR; PRAGMATISMO CONTEMPORÁNEO; ONTOLOGÍA SOCIAL; EPISTEMOLOGÍA GENÉTICA; RICHARD RORTY.

(C) Contrastes. Revista Internacional de Filosofía, vol. XXII-N² (2017), pp. 39-58. ISSN: 1136-4076 Departamento de Filosofía, Universidad de Málaga, Facultad de Filosofía y Letras Campus de Teatinos, E-29071 Málaga (España) 


\begin{abstract}
I will relate some social and epistemic aspects involved in the conceptual development of the genetic model in the early Molecular Biology. I will use the link between Biology and Physics as a framework, which supports such assumptions, providing new methodologies, but mainly as a framework that provides a model of objectivity developed within Modern Tradition. Fina1ly, I will interpret this relationship from the pragmatist perspective to embrace Rorty's thesis on «the ontological priority of the social» which implies understanding biology as a part of a general cultural politics.
\end{abstract}

KEY-WORDS

MOLECULAR BIOLOGY; NEO-PRAGMATISM, SOCIAL ONTOLOGY; GENETIC EPISTEMOLOGY; RICHARD RORTY.

\title{
I. INTRODUCCIÓN
}

Según Tabery, Piotrowska, y Darden en la Stanford Encyclopedia of Philosophy (2016), la biología molecular surge de la convergencia de diferentes disciplinas como la genética, la física o la química al abordar un mismo problema, a saber, la naturaleza de la herencia. Para la década de 1920, el concepto del gen era considerado como el factor principal de ésta, en tanto que unidad de transmisión, recombinación, mutación y funcionamiento de la vida. Si bien los genes eran tratados como elementos abstractos, también se pensaba que tenían una base material, hipotéticamente proteínica, cuya estructura podía ser relativamente explorada a través de experimentos basados en cruzas cuantificables y visibles en organismos modelos y sus mutaciones (Rheinberger 2015). Estas características le ubicaban conceptual y metodológicamente dentro del proceso de molecularización de la vida, ${ }^{1}$ si bien aún en un estado insipiente. Por consiguiente, aunque es cierto que el esclarecimiento de la estructura molecular del gen fue un proceso paulatino que comenzó al resolverse más claramente a partir de 1945 con el estudio de las moléculas implicadas, ${ }^{2}$ desde la década de 1930 dicho concepto tiene una conexión fundamental como parte de la disciplina que se estaba surgiendo bajo el nombre de biología molecular. ${ }^{3}$ En definitiva, el consenso científico apuntaba al hecho de que estas entidades conformaban la unidad de la vida a nivel molecular, y por consiguiente, sus

1 En tanto que el modelo supone una explicación en términos físico-químicos de las moléculas constitutivas y hace uso de metodologías intervencionistas provenientes de la física, además de responder parcialmente al problema que articuló el proceso de molecularización.

2 En 1941 George Beadle y E.L. Tatum introducen el hongo Neurospora como organismo modelo con el que establecen la relación un gen-una enzima, es decir, que los genes son elementos portadores de información que codifican enzimas y en 1945 Oswald Avery, Colin McLeod y Maclyn McCarty encuentran que el «principio transformador» es el ADN.

3 Siguiendo de nuevo a Tabery, et. ál. (2016), la biología molecular se originó en la década de 1930 y 1940 y se institucionalizó en las décadas de 1950 y 1960. 
funciones, naturaleza y estructura jugaron históricamente un papel central en los procesos biológicos durante dicho surgimiento (Yoxen 1982, p.130). Así, aunque la historia de la biología molecular y la del gen en la teoría cromosómica de la herencia transcurrieron parcialmente en paralelo y la primera no se reduce a una genética molecularizada, no estaban en absoluto desconectadas. Ejemplo de ello es que los personajes y episodios que a menudo encontramos en uno y otro caso coinciden o se cruzan en las diferentes narrativas y análisis. El presente trabajo parte de la idea de que el desarrollo del concepto y modelo del gen durante esas décadas forma una parte importante de la historia de la biología molecular, dicha conexión se hace patente en el hecho de que ambos paradigmas convergen de manera fundamental en la década de 1950 durante el surgimiento del modelo de la doble hélice.

Por otro lado, esta referida historia sobre el origen de la biología molecular ha sido ampliamente explorada por diversos estudiosos de la ciencia. En particular, desde de la década de 1980 surgieron diversos trabajos que reconstruyen la influencia que determinados factores sociales tuvieron para institucionalizar y definir el estudio de la vida a nivel molecular y el modelo epistemológico que subyace en él (Sapp 1987; Yoxen 1982; Kay 1997; Kohler 1976). Si bien los resultados son dispares y controvertibles, una parte de estos planteamientos recurre a la relación foucaultiana entre verdad y poder para explicar, por ejemplo, el papel de intereses sociales, económicos o ideológicos de determinados sectores que promovieron este paradigma. El interés de este trabajo también radica en tomar como punto de partida dichos estudios que muestran, como afirma Chadarevian (2002), que la biología molecular «fue producida tanto el laboratorio como en la arena política y pública» ${ }^{4}$ (p.1).

Con estos puntos de partida, intentaré complementar la explicación sobre el éxito del modelo nuclear del gen en esta etapa molecularmente originaria que, aunado a los factores sociales promotores de su hegemonía, obtuvo parte de su legitimación gracias a una metafísica cientificista que cimentaba la noción de objetividad clásica. Dicha metafísica estaba depositada en la física como modelo de conocimiento y realidad. El éxito del modelo, desde mi perspectiva, no puede ser explicado sin estos elementos. Así, las características epistemológicas del concepto del gen dentro de la teoría cromosómica de la herencia están insertadas en un cuadro histórico en el cual se encuentran entrelazadas con determinados valores sociales, aunque estos no sean homogéneos ni unívocos y a menudo son invisibilizados por dicho concepto de objetividad. Asimismo, sugeriré que este vínculo puede ser leído a partir de algunas tesis pragmatistas que ilumina

$4[\ldots]$ was produced as much in the laboratory as in the political and the public arena» (La traducción es mía). 
una reflexión interesante sobre la naturaleza y el papel de la biología molecular en la cultura.

\section{EL AMBIENTE SOCIAL}

Si consideramos la década de 1920 como el periodo de consolidación del modelo nuclear de la herencia, ${ }^{5}$ podemos sostener, admitiendo ciertas simplificaciones, que para la década de 1930 había un modelo básico, aunque incompleto del gen. Dicho modelo, conocido como teoría nuclear o cromosómica de la herencia, incluía al gen como la unidad fundamental de la vida, tanto funcional como estructuralmente, alojado en el núcleo de la célula y un conjunto de técnicas propias de la disciplina, ${ }^{6}$ así como el estudio de las proteínas como primer tema coherente e interdisciplinario de la biología molecular (Abir-Am 1997, p. 119). Para este momento, el modelo nuclear establecía objetos, normas y métodos claros accesibles a la investigación sobre la herencia (Sapp 1987, p. 87), además de que para algunos protagonistas de este desarrollo, como el genetista Herman Muller, el problema de la vida se reducía a resolver la estructura del gen (Yoxen 1982, p.131).

Como he dicho, diversos estudios han intentado explicar la hegemonía de este modelo a partir de un conjunto de factores sociales que proporcionaron sus condiciones de posibilidad y facilitaron su institución y predominio cognitivo. Si bien estas posturas son polémicas, algunas de ellas consideran que tal predominio fue facilitado por un desarrollo social principalmente norteamericano. Estos análisis sugieren un escenario en el que un ambiente tecnócrata en la sociedad liberal y pragmática estadounidense posibilitaron, a través de distintas estructuras, esta hegemonía. Un elemento clave de estos estudios es el del papel que tuvo la Fundación Rockefeller a través del financiamiento dirigido a los proyectos de las ciencias de la vida en general. Aunque algunos lo consideran definitivamente determinante para la institucionalización de la molecularización de la biología y el predominio del modelo nuclear de la herencia (Kay 1993; Yoxen 1982; Kohler 1976), otros limitan su impacto a una etapa que no obtuvo las claves fundamentales del modelo de la doble hélice. Según esta última lectura, aunque la fundación hizo una trasferencia de metodologías y técnicas, así como de científicos formados en física a los problemas de la vida, ésta se

5 Para la década 1920 se conocían las características básicas de la herencia mendeliana (Mayr 1982,p. 794); había una base física para los genes en los cromosomas y cierta aceptación en la comunidad de biólogos de que el núcleo albergaba dichos genes que constituían el factor principal de crecimiento, desarrollo y transmisión de cualidades específicas de célula a célula, de una generación a otra (Sapp 1987).

6 Como la producción artificial de mutaciones por radiación o el estudio de microorganismos para estudiar los fenómenos vitales en sus niveles mínimos. 
caracterizó por una mera instrumentación y dominación que no entendió y profundizó correctamente en los problemas de la biología (Abir-Am 1982). De tal forma que la política de la fundación no logró los giros conceptuales necesarios para obtener los resultados clave que determinarían durante la siguientes décadas a la nueva disciplina, debido a esta forma de implementar políticas de financiamiento (Abir-Am 2002), que se concibió como una mera «colonización» de una ciencia por parte de otra.

Otros estudios apuntan a un escenario internacional en el que interactúan políticas, prácticas científicas, tradiciones y enfoques articulados desde diversas naciones que dominan la disciplina en diversos momentos (Chadarevian 2002, Abir-Am 2001, Gaudillière 1997), como Francia o Gran Bretaña. Si bien está claro que la Fundación Rockefeller no fue la única institución que subvencionó las investigaciones sobre la biología molecular y la genética del modelo nuclear ni Estados Unidos fue el único país que contribuyó a establecer su dominio, podemos decir que durante el periodo al que nos restringimos, entre $1930 \mathrm{y}$ 1940, este país tuvo un papel muy importante en su evolución, etapa en que la Fundación jugó un papel relevante en Estados Unidos y a través de su financiamiento en otros grupos de investigación en Europa. De tal forma que ésta logró permear en las estructuras académicas que financiaba a través de su participación. Con ello, estuvo en posición de promover un trabajo interdisciplinar y un cierto sentido industrial que compartían los directores y una élite de la que la Fundación era representativa (Kay 1993, p. 8). Señal de ello es que en su seno se gestó el propio nombre de biología molecular. ${ }^{7}$

De acuerdo con la historiadora Lily E. Kay, el significado del compromiso filantrópico de la fundación con el modelo tenía dos niveles: el económico y el ideológico. El primero de carácter materialista y utilitario era un intento de propiciar condiciones favorables para el crecimiento de la productividad económica a partir de aplicaciones en la agricultura y la crianza de animales. De esta forma, los criadores también tuvieron un papel relevante en la visión de la genética porque era económicamente rentable al desarrollar la mejoría en calidad o cantidad de cultivos, lo que atrajo financiamiento privado y público. Adicionalmente, los programas de agricultura proporcionaron genetistas, estudiantes para llenar los cursos en las universidades, y una vez institucionalizada la disciplina se convirtió en una relación entre experto y cliente, genetista y criador (Sapp 1987, p. 47).

En el nivel ideológico, la Fundación buscaba desarrollar un tipo de ciencia que a largo plazo permitiera un control social a través de la herencia para «mejorar» la conducta humana de acuerdo a determinados valores protestantes.

7 El director de la División de Ciencias Naturales, Warren Weaver introdujo el término «biología molecular» en un reporte de la Fundación en 1938 (Weaver 1970). 
Así, buscaban dirigir su concepto de prosperidad social a partir de una base natural realizada en la ingeniería humana. Como resultado, elaboró un programa definido y coordinado de políticas científicas para financiar la investigación del modelo cromosómico de la herencia donde convergían capital intelectual, económico, una agenda social y determinadas metas científicas (Kay 1993).

Como es bien sabido, una figura clave en este papel de la Fundación fue Warren Weaver, director del área de ciencias naturales desde 1932, y realizador del giro en la política de la fundación que dirigió el apoyo a las ciencias de la vida con atención a la física, química y matemáticas como fundamento. Concretamente, Weaver buscaba que la biología llegara a ser como la física: cuantitativa y haciendo uso de sus métodos. Así, unificó y sistematizó un conjunto de investigaciones en una disciplina que en 1938 llamaría biología molecular, acelerando el movimiento de físicos y químicos a la biología y dando apoyo a la aplicación de sus técnicas en ella (Bartels 1984, p. 303). En definitiva, se convirtió en un manager de la ciencia, influenciando la formación de una política nacional e internacional de investigación científica (Kohler 1976, p.27).

Adicionalmente, otros estudios señalan una política norteamericana educativa flexible y poco controlada por el Estado, donde la filantropía privada tiene un papel relevante en contraste con países como Alemania y Francia, posibilitó que una infraestructura y medios de transmisión del conocimiento relativamente autónomos institucionalizaran una nueva disciplina con sus propios objetivos. Algunos estudios señalan instituciones como la revista Genetics (1916) y un conjunto de sociedades que jugaron un papel importante en mantener la preferencia del modelo cromosómico sobre las alternativas. Además, los rápidos resultados a través del análisis genético, los métodos y técnicas que fueron muy prolíficas hacían que los estudiantes se sintieran atraídos al área donde tenían buenas oportunidades de éxito.

Finalmente, Kay también señala que en el ámbito de la psicología, la influencia del conductismo de Watson era un lugar común en la época, y dentro de ella la predicción y el control del comportamiento era considerada como una meta. Algunos psicólogos y sociólogos se inclinaban por la búsqueda de una física social en el sentido comptiano (Kay 1993, p. 35). Así, estudiar los procesos vitales bajo las premisas del modelo cromosómico proporcionaba un puente hacia la psiquiatría, la neurociencia, en cercana relación con el concepto de psicobiología.

Según la perspectiva anterior este ambiente social, industrial, liberal y pragmático, se traduce en un conjunto de valores que establecen una política externa de la ciencia, y ésta resuena con la dinámica interna de la ciencia institucional. La infraestructura y los medios que proporciona este contexto promueven que en la lucha por obtener la autoridad cognitiva el modelo del gen sea hegemónico, aunado a su éxito predictivo. Sin embargo, esto no es suficiente 
para explicar el dominio del modelo. Hacía falta un marco epistemológico que le diera autoridad en términos de objetividad científica. Para ello el modelo de la física clásica resultó útil.

\section{LA CONFIGURACIÓN DEL GEN COMO ÁTOMO BIOLÓGICO}

Es bien conocido que el ambiente epistemológico dominante en el desarrollo temprano del concepto del gen obedecía en parte a una analogía, tanto conceptual como metodológica, con las ciencias físicas. Analogía que fue explícitamente propuesta por algunos de los personajes protagónicos en su desarrollo como $\mathrm{H}$. J. Muller, además de promovida por patrocinadores científicos y aceptada, implícita o explícitamente, por la mayoría de los investigadores. Dicho paralelismo consistía en proponer al gen como la unidad de la vida, de la misma forma en que el átomo constituía la unidad de la materia; así como para la física, según Muller, la transmutación de elementos era el problema central, para la biología lo era el de la mutación. El uso de la radiación como forma de exploración de las unidades vitales ofrece un paralelismo metodológico.

De este modo, el gen, como unidad hereditaria, abstracta es, lógica y temporalmente anterior a la vida, es su unidad fundamental y se estudia a través de mutaciones, de cambios discretos (Fox 1990, p.399). En un predominante ambiente de reduccionismo ontológico, de mecanicismo y causalidad determinista, se concebía que todo organismo se reducía a la explicación de estas entidades físico-químicas. De igual forma, el lenguaje lógico y matemático; la medición y el control de variables debían ocupar un lugar central en esa nueva biología.

Ya desde la década de 1920, Morgan y Muller pensaban que la teoría de la herencia podría llegar a ser la base que uniera toda la biología en una disciplina. Si como todo el mundo pensaba, el gen era una enzima o una proteína requería de explicación en términos físico-químicos y funcionaba como una unidad estructural al tener una propiedad fundamental de replicación idéntica; responsable de mantener las propiedades fisiológicas y morfológicas, así como de producir las diferencias. Continuidad y variación eran las preguntas clave en esos años; cómo se transmiten los caracteres a la siguiente generación y cómo se produce la variedad por mutación. Este modelo prolífico llevó a la acumulación de numerosos datos y resultados que clarificaron consistentemente distintos aspectos del proceso de la transmisión genética y refutaron parcialmente las teorías alternativas. Ello alentaba la idea de reducir el proceso de la vida a explicar la estructura del gen.

Así, este modelo enfatizaba la unidad conceptual de la vida, aglutinando un gran rango de fenómenos bajo el término de gen. En ella, la diversidad biológica era resultado de combinaciones de relativamente pocas leyes y principios fundamentales que debían venir de la física y la química en un esquema de causación ascendente, combinado con una perspectiva intervencionista de 
la biología. Esta concepción coincide con la descripción que hacen Serrano y Caponi en relación a la lectura que hace Weaver de la ciencia: «La historia de la ciencia, según la considera Weaver, es la historia de una obsesión por encontrar aquellos principios que nos permitan dar cuenta de la existencia de una unidad subyacente a la multiplicidad de fenómenos con los que nos ponen en contacto nuestros sentidos». (Serrano \& Caponi 2014, p. 146)

Así, aunque queda claro que la física es un modelo que debe aplicarse a la biología, resulta necesario precisar qué concepto de física tienen en mente para realizar la analogía.

A principios del siglo pasado la física vivió una gran revolución con el surgimiento de la teoría cuántica que obligó a una profunda reconsideración de las nociones epistémicas y principios de realidad básicos sobre los que se edificaba la física clásica que había surgido en el siglo XVII. Concepciones como causalidad, objetividad y determinismo en sus sentidos clásicos, parecían enfrentar una crisis a partir de la interpretación de Copenhague de 1927. Según los autores de la teoría, ésta tenía un carácter terminantemente probabilista, los fenómenos cuánticos entendidos como una relación entre instrumento y objeto obligaron a una redefinición de realidad y de objetividad, perdiendo su sentido clásico como realidad independiente (Bohr 1934). Ello llevó a un periodo en el que la física se vio obligada a repensar estos términos y sugería una actitud problemática hacia la noción clásica de objetividad, el reduccionismo y la causalidad determinista.

Esta revolución obligó a científicos y particularmente a la filosofía de la ciencia a replantear una cientificidad no clásica y, entre muchas otras cosas, se sugirió repensar la relación entre biología y física. En particular, dos congresos en el año 1931 en Londres abordaron la reelaboración de la estructura que históricamente se había pensado como jerárquica y reduccionista entre física y biología (Abir-Am 1997, p. 112). Una muestra de ello, es que el discurso que sostenían algunas figuras icónicas de la física cuántica que incursionaron en la biología, como Delbrück o Stent fueron antirreduccionistas y/o acausales (Olby 1971; Kay, 1985). Asimismo, jóvenes vanguardistas identificados con el marxismo veían el reduccionismo entre física y biología como un reflejo de las contradicciones capitalistas y abogaban por una relación complementaria ellas que encarnaría una ciencia liberadora del futuro ${ }^{8}$ (Abir-Am 1997, p. 114).

Conocedor de los cambios ocurridos, el propio Weaver pensaba que la física cuántica nos había enseñado la imposibilidad de comprender un fenómeno, ya que solamente podemos controlarlos o manipularlos, pues el determinismo estaba en tela de juicio, la objetividad carecía de apoyo y la lógica es débil e

8 J.D. Bernal biofísico y cristalógrafo de rayos X y C.H. Waddington embriólogo y genetista. 
incompleta (Serrano \& Caponi 2014 pp. 144-5). ${ }^{9}$ Su modelo limitado a la caja negra de la que podemos controlar variables parecía más bien revivir una versión restringida de la concepción clásica, a pesar de que parte de las técnicas de la física que llevaron al terreno biológico ya se movían en los nuevos paradigmas.

Si bien este panorama muestra que los teóricos de la biología estaban atentos al debate en física, no era a una imagen novedosa de la ciencia con términos y relaciones en crisis, discusión y renovación, la que dominaba en la analogía del modelo nuclear. Sin embargo, los estudios parecen indicar que no hay un consenso sobre la forma en que la física influyó en la configuración de la molecularización de la genética y la biología en general, pues como hemos señalado antes, sólo los físicos que se vieron totalmente inmersos en la problemática propiamente biológica tuvieron un papel relevante en su configuración. Además, la cuestión del reduccionismo es polémica, ya sea porque algunos se inspiraron en los nuevos resultados cuánticos y pensaban encontrar en la biología nuevos principios no reducibles a la física, o porque no para todos la reducción metodológica significaba una reducción ontológica entre biología y física (Olby 1990, p.511-12). Lo que resulta innegable es que la analogía inicial con el átomo, las aproximaciones metodológicas, técnicas, y la meta de explicar los conceptos de mutación, gen, desarrollo, etc. en términos físico-químicos apela a cierta reducción o a una resonancia innegable con la física, si bien esta es heterogénea y ambigua.

\section{EL GEN COMO HECHO Y VALOR}

Siguiendo al filósofo Richard Rorty, el modelo epistemológico de ciencia clásico se consolidó en el contexto filosófico de la modernidad donde lo científico, prototípicamente representado por la física, se configuró como lenguaje de la Naturaleza en sí misma y de la realidad. Como resultado de esta configuración, la epistemología moderna insistió en que la filosofía debía ser modelada por una metafísica científica, separada del arte o la política, y se propuso establecer con ella un marco de conocimiento ahistórico y universal que sirviera de fundamento a la cultura. De esta forma, la tradición naturalizó la idea de que el éxito del vocabulario reduccionista y matemático de Galileo radicaba en parte en el hecho de estar despojado de significado moral o interés humano (Rorty 1996, p. 274). Con ello, se institucionalizó la idea de que cuánto menor sea la significación moral de nuestro vocabulario resulta más probable que seamos «científicos», que eliminemos las ideas subjetivas de un lenguaje o que describamos la realidad tal como es y la controlemos. En síntesis, la cultura se apropió de la idea de que es más posible que un término se refiera a lo real si es moralmente insignificante y aparece en generalizaciones efectivas para la predicción (ibíd., p.277). Este

9 La interpretación de Bohr y Heinseberg es distinta. 
vocabulario idealmente concebido parecía realizarse por primera vez cuando Newton formuló un lenguaje a partir de dichas generalizaciones. Como resultado, estas nociones nos ligaron a una noción de objetividad que se asoció con ser independiente de descripciones meramente humanas o en relación a nosotros y nuestros propósitos (Rorty 1991).

Siguiendo esta lectura en el caso que nos ocupa, lo que quiero sugerir es que la analogía y resonancia con la física en la gestación y consolidación del modelo genético nuclear significaban en parte que ésta encontraba su camino newtoniano, en el sentido antes descrito. La analogía, el reduccionismo y los métodos adoptados proporcionaban al modelo biológico objetividad, por tanto, un estatus ontológico de realidad fundado en esta noción epistemológica clásica de ciencia.

Sin embargo, siguiendo también a Rorty en su crítica a la modernidad, las premisas de esta concepción filosófica de objetividad y realidad obedecen a determinadas circunstancias históricas opcionales que parecen agotadas ante el fracaso de ser inequívocamente formuladas en ciencia o en filosofía. ${ }^{10} \mathrm{En}$ contraposición, en su perspectiva podemos seguir la conceptualización del conocimiento y la ciencia, no como una representación de la realidad en sí, sino como un conjunto de prácticas cuyo éxito sólo puede ser entendido en su trasfondo histórico y su contexto social. Además, las dificultades para distinguir entre cuestiones de hecho y significado, entre mundo y lenguaje o teoría y observación señaladas por la filosofía del siglo pasado llevan al pragmatismo de Rorty a seguir a James y a Dewey, en una posición paralela a Nietzsche y Foucault, sobre la relación entre hecho y valor, así como entre verdad y poder.

Si bien durante el siglo XX en la filosofía se abordó la cuestión de los valores en la ciencia por parte de autores como Kuhn, Hanson o Feyerabend y posteriormente con particular énfasis la dimensión axiológica del trabajo científico (Echeverría 2002; Douglas 2007), voy a seguir el planteamiento del pragmatismo clásico de Dewey y su interpretación en Rorty. Ello porque estos planteamientos se centran en los aspectos que quiero señalar y que el pragmatismo de Rorty es suficientemente radical para llegar a las conclusiones que ofrezco.

En su libro Logic: The Theroy of Inquiry (1986), el pragmatista norteamericano John Dewey describe y justifica que, aunque la investigación tiene lugar en una situación objetiva y pública, siempre involucra sujetos y busca la resolución de un problema. Este punto de partida y su posterior caracterización de la investigación le llevará a la disolución de la distinción tradicional entre hecho y valor. El núcleo del argumento es que tal distinción equivale al contraste entre

10 Rorty describe cómo la filosofía ha fracasado reiteradamente en explicar del éxito científico en términos de la correspondencia entre lenguaje de la naturaleza y jerga científica, por lo que su sugerencia es la renuncia a dicha explicación (Rorty 1996, p. 275). 
aquello que es independiente de un fin (hecho) y aquello que está relacionado con una pretensión (valor); pero todas las investigaciones tienen pretensiones. De tal forma que, por un lado, en toda experiencia existe una valoración, aquella que motiva y orienta la investigación a un fin. Por otro, un juicio de valor no es externo a la experiencia pues depende de sus consecuencias y, por tanto, de las conclusiones de la investigación. Hechos y valores no son ajenos. Para establecer hechos requerimos hacer valoraciones y toda valoración está fundada en determinados hechos. El mundo de la experiencia tiene importancia moral en función de que da condiciones para que puedan cumplirse determinados fines, pero estos fines responden al deseo de resolver la problemática que originó la investigación. Por tanto, no son fines permanentes y externos a toda cuestión empírica. Hay una continuidad entre hechos y valores en el proceso del conocimiento (Faerna 1996, pp. 189-97).

Rorty recupera esta disolución para sostener una noción de objetividad que no apela a hechos desprovistos de valores o de intereses humanos, que trasciende o elimina elementos humanos, sino a una intersubjetividad de una comunidad tan amplia como sea posible, pero que siempre está sujeta a los objetivos que nos proponemos las distintas comunidades, en este caso, la de los científicos (Rorty 1991).

Desde esta mirada, el concepto del gen se encontraba necesariamente ligado a determinados fines y, por tanto, valores conectados directa o indirectamente con las cuestiones empíricas de la vida. Por tanto, como argumentaré a continuación, el gen constituía hechos y valores simultáneamente. Aunque este conjunto de valores no era único o consistente ni estaba ligado con el modelo científico de forma necesaria, sí jugó un papel relevante en su desarrollo .

El modelo epistemológico del gen que he esbozado soporta determinadas valoraciones a distintos niveles, desde el de cada científico, su apreciación de determinada concepción de la física como modelo de conocimiento, hasta un concepto de objetividad y rigor generalizado que las ciencias físicas tradicionalmente proporcionan, como antes he descrito. Al mismo tiempo, esos mismos supuestos sostenían eficientemente los fines de algunos grupos, como la fundación Rockefeller o los grupos a los que ésta representaba, para alcanzar la autoridad epistémica e institucionalizar sus perspectivas de lo que la vida es.

Sin embargo, más sutil resulta la asociación e interdependencia del modelo con determinadas dimensiones sociales que se dieron durante su desarrollo. Por ejemplo, un elemento central en éste ocurre alrededor del debate reduccionismo-holismo, a su vez vinculado a determinadas formas ideológicas de la vida social. Una muestra de ello era la forma en la que los genetistas en la controversia utilizaron una variedad de metáforas políticas y económicas cuando discutían los modelos de control genético en la célula como: «monopolio nuclear», «agentes dictatoriales», «organización democrática de la célula», «la 
célula como un imperio», «república de cromosomas», etc. (Sapp 1987, p.196). Particularmente, como ya se dijo, para los científicos británicos promotores de ideales marxistas, el reduccionismo simbolizaba las contradicciones capitalistas del sistema social. Por el contrario, para las visiones más conservadoras, como las de la Fundación Rockefeller, éste vislumbraba una psico y sociobiología también reduccionistas que, sin embargo, simbolizaban un control social asociado con los valores protestantes.

Asimismo, es posible establecer la asociación de determinadas preferencias científicas con el ambiente social donde se gestaron y consolidaron, a saber, con determinada cultura nacional o culturas de laboratorio enraizadas en tradiciones locales (Gaudilliére 1997, p. 46). Tenemos el nacionalismo francés defensor del lamarckismo y la fisiología, el pragmatismo y el liberalismo norteamericano comprometidos con la genética nuclear o el estatismo alemán vinculado con la embriología experimental. Esto explicaría en parte que la mayoría de las pocas oposiciones al reduccionismo del modelo nuclear sucedieron en los contextos alemán (Mayr 1982, p. 732) y francés, en donde además había control estatal de la investigación y menos inversión privada. De acuerdo con algunos estudios, estos modelos y sus experimentos fueron mayormente desestimados debido a una inconmensurabilidad metodológica. ${ }^{11}$

Sin embargo, otros análisis también señalan que la colaboración internacional que caracterizó el desarrollo de este modelo tuvo una doble función pragmática y legitimadora; por un lado sirvió para obtener beneficios políticoeconómicos de las inversiones en ciencia y, por otro, fue fuente de objetividad al permitir superar las tradiciones locales y nacionalistas (Abir-Am 1997, pp. 139-143).

Además, como hemos dicho, la concepción de la vida que este marco epistemológico posibilitaba era un vocabulario útil para los fines de determinados sectores sociales en los Estados Unidos. Fue un vocabulario que vislumbraba tanto el proyecto del beneficio económico como el ideológico de la ingeniería humana, al soportar si bien indirectamente, la realización de un proyecto eugenésico, según el cual sería posible dirigir la evolución de la especie y eliminar los rasgos «indeseados» de la humanidad. Esto es, permitía establecer un vínculo, aunque fuera ambiguo y potencial, entre pequeñas unidades de materia animada y el control de la personalidad concebida desde la genética. En palabras de Weaver: «Hemos elegido esta actividad [...] debido a una convicción de que

11 Parte de la comunidad científica insistió en una visión holista de la vida a través del papel del citoplasma en la herencia. Sin embargo, esta postura fue marginal y tampoco logró estudios que se consideraran sistemáticos, pues se trataba de técnicas y conceptos no estandarizadas por los criterios de la teoría nuclear (Sapp 1987). 
en tales estudios con el tiempo van a recaer los (únicos?) fundamentos firmes para el entendimiento de la racionalización del comportamiento humano». ${ }^{12}$

En resumen, las metáforas de que echaron mano los distintos grupos científicos reflejan los elementos ideológicos involucrados en la disputa y las relaciones de poder, sus intereses, tanto a nivel individual como la nivel de grupos e instituciones. Un concepto de vida posibilitaba determinados fines, y éstos a su vez perfilaban un concepto de vida. Por tanto, el modelo del gen y la experiencia en la biología no describe meramente hechos, sino que implica ciertas significaciones morales e intereses humanos que, aunque no son consistentes entre sí ni están perfectamente definidos, juegan un papel en el lugar que ocupará en la práctica científica.

Esta dimensión valorativa de los modelos científicos a menudo se oculta cuando se sigue el modelo de objetividad como neutralidad axiológica y completa independencia de la referencia a lo humano que esbocé en la sección anterior. Si bien no hay un acuerdo por parte de los estudiosos de la biología molecular sobre si Weaver logró que la biología fuese como la física en el sentido particular que antes hemos descrito o si ésta siguió un desarrollo propio, ${ }^{13}$ el hecho de que el modelo del gen surgiera justamente de una analogía con la física, modelo de objetividad en dicho sentido clásico, contribuyó a darle legitimidad la teoría cromosómica de la herencia y a que, en parte, se ignorara su asociación con este conjunto diverso y ambiguo de valores.

Sin embargo, la realidad material biológica «independiente», los experimentos y resultados científicos, no actúan solos en la producción de conocimiento, sino que una variedad de estructuras sociales, simbólicas y materiales, posibilitan determinados escenarios cognitivos y viceversa. Resulta innegable que cualesquiera términos de los que se haga uso para describir una entidad, aunque sea científica, adquieren un carácter evaluativo sin perder por ello su carácter real y verdadero. Se trata más bien de reconocer que la propuesta de separar los términos evaluativos en un lenguaje aparte, haciendo de su ausencia un criterio de cientificidad, resulta irrealizable. Con ello seguiríamos más una noción de objetividad intersubjetiva en el modelo, que en parte fue posible por la dinámica internacional e interdisciplinaria de la actividad científica, siguiendo a Abir-Am (1997), pero que nada tiene que ver con la ausencia de valores ni con la independencia de los hechos de nuestras descripciones.

12 «We have chosen this activity [...] because of a conviction that such studies will in time lay the (only?) sure foundation for the understanding and rationalization of human behavior» (La traducción es mía) (Weaver 1935).

13 Aunque es difícil defender que la biología se hiciera como la física, en el sentido reduccionista, debido a la complejización de la genética y la biología molecular en general. Sin embargo, el propósito de Weaver sí se alcanzo, en términos de técnica, de cierta formalización, y de explicación en términos físico-químicos. 
Weaver es una imagen muy ilustrativa de esta simbiosis entre hechos y valores en la biología molecular, así como de la metafísica moderna del conocimiento científico que ignora dicho vínculo. Pues al tiempo que estaba comprometido con los valores tecnocráticos y protestantes de la Fundación, también pensaba que la ciencia era importante en sí misma (Weaver 1961). Consideraba que la esencia de la ciencia es su método, honestidad, actitud abierta, amor a la verdad, ejemplo de cooperación y su carácter universal, por lo que había que aplicarla en áreas sociales y políticas. Esto abría el espacio para que se cultivara a las élites científicas para combatir «disfunciones» sociales en consonancia con las ideas de la socio y psico-biología. En definitiva, los hechos del modelo nuclear sostenían los valores con los que estaba comprometido, al tiempo que su noción de ciencia objetiva ocultaba dicho sustento. Podemos concluir, siguiendo a Kohler, que «el modelo estaba basado en un proceso de racionalización de la vida en donde la física era el modelo de racionalidad y objetividad, lo que significaba una utilidad social potencial, al sugerir la posibilidad de traer un orden racional al ámbito social» (Kohler 1976, p. 281).

\section{DEFENDIENDO LA PRIORIDAD ONTOLÓGICA DE LO SOCIAL}

Este ejemplo nos muestra que la producción de conocimiento constituye un poder social y sus elementos epistémicos y ontológicos están determinados y determinan esa estructura social, ideológica, en el sentido de ser necesariamente evaluativa. Sin embargo, no es ideológica como algo que distorsiona nuestra visión directa de la realidad biológica ya que ésta parece una tarea imposible, sino, parafraseando al filósofo esloveno Slavoj Žižek, como nuestra relación espontánea con el entorno. En este sentido, los productos de la ciencia y la tecnología funcionan porque están inmersos en estas prácticas culturales, establecidas y naturalizadas en formas de producción de verdad, como la predicción y el control.

Ello no supone «desconfiar» de nuestras teorías por ser subjetivas o ideológicas. Pues todo vocabulario involucra valores en formas que pueden ser más unívocas o más borrosas e indeterminadas. Es verdad que cuando adoptamos los términos de un vocabulario, cuando creemos en una entidad científica nueva, obtenemos ciertos compromisos existenciales. Sin embargo, un compromiso existencial obedece a una determinada descripción: en este caso nos comprometemos con un sentido particular de la existencia del gen que tiene su propia red de creencias establecidas en el modelo nuclear de la herencia. Así, para un pragmatista, como Rorty, los únicos elementos primordiales en ellas, son los que hacen posibles las aplicaciones de las normas sociales que articulan las descripciones y las inferencias dentro de ellas. De esta forma, la articulación inferencial de conceptos en las prácticas lingüísticas, como lo es la ciencia, nos lleva a que la distinción entre lo que los genes son o no, es inherente a lo social. 
Por tanto, los genes son artefactos de la cultura en la medida en que cualquier hecho que les involucre también implica necesariamente un conjunto de valores. No obstante, parte de la dimensión valorativa que permea en la ciencia es sutil, pues radica en los supuestos básicos de los cuales los científicos no suelen ser conscientes debido a que creen que están realizado generalizaciones axiológicamente neutras de corte galileano, idea sustentada implícitamente en el modelo de la física como modelo de objetividad y racionalidad científica. Por lo tanto, se trata de explicitar que dicha dimensión tiene un efecto en las formas de explicación y puede servir para reforzar o naturalizar ciertas actitudes sociales que dieron origen a tales supuestos (Lewontin 1991, p. 14).

Rechazar la distinción entre hecho y valor que se ha cuestionado aquí y, con ello, asumir una noción de objetividad que tiene que ver más con el acuerdo que con la independencia de nuestras descripciones, implica un desplazamiento de lo meramente epistemológico hacia lo ético y político, como bien apunta el propio Rorty. Pues ninguno de nuestros lenguajes mostraría la forma de ser del «propio mundo o la realidad» sino que son instrumentos que son más o menos útiles para las diversas metas que como comunidad nos planteamos. Si asumimos este desplazamiento en el discurso científico, la explicitación de estos elementos en la biología involucran a los científicos, a la reflexión filosófica de la biología y al lugar que ésta ocupa en la cultura. Significa dar sentido a una perspectiva de las entidades de la biología que recae en una normatividad social, histórica y desprovista de metafísica. Esta tesis es a lo que Rorty (2010) ha denominado «la prioridad ontológica de lo social». Interpretando así las descripciones científicas, concluimos que la autoridad tradicionalmente atribuida a lo no humano, la realidad en sí misma biológica o física admite una explicación sociológica, sin ser menos real u objetiva por ello.

Estas afirmaciones pueden parecer anti-intuitivas, pues el empirismo aún es muy habitual y sus prácticas sociales han formado nuestras intuiciones; la idea de que el mundo de la naturaleza se expresa en sus propios términos a través de los hechos y los experimentos. Pero repensando las intuiciones como prácticas sociales, nos damos cuenta que no existe lenguaje que sea capaz de indicarnos definitivamente el alcance de la existencia, en particular, de las entidades de la ciencia, como son los genes. La propia complejidad y polémica historia del gen da cuenta de ello. Si como afirma Rheinberger (2000, p. 222) en el origen de la biología molecular el concepto del gen surge sin una definición comprehensiva, exacta y rígida, la situación no ha mejorado a lo largo de su historia. En más de 100 años de investigación han proliferado los conceptos de gen, algunas veces complementarios y otras contradictorios. Ello ha generado numerosos debates para sustituir, generalizar, redefinir o dividir el concepto del gen (Rheinberger 2015). El análisis de diferentes premisas que subyacen en él, los problemas de 
ambigüedad, reducción o causalidad que se han explorado en él le hacen que siga siendo como dice Falk (2000) «un concepto en tensión».

Este proceso se vuelve más comprensible cuando pensamos su desarrollo como parte de una práctica cultural como es la biología que enlaza prácticas de laboratorio, valores epistémicos y no epistémicos acoplados de distintas formas en diferentes grupos, condiciones institucionales públicas y políticas de estado, etc. Sin embargo, en consonancia con la prioridad ontológica de lo social, mirar en estos términos al gen y a la biología no es un descubrimiento empírico o una necesidad conceptual; es articular una posición cultural señalando las ventajas sociales de su explicación, ya que articula otro tipo de relación entre biología y cultura.

Así, el punto clave de entender los genes como práctica social radica en la forma en que entendemos la autoridad epistémica, establecida no por la experiencia en sí, sino por la comunidad que asume y utiliza tales instrumentos. Estas consecuencias son de gran envergadura, aún cuando el desarrollo del modelo de la herencia que aquí hemos explorado se ha modificado enormemente en una serie de relaciones mucho más compleja. ${ }^{14}$ Sin embargo, ello no disminuye la importancia de la reflexión antropológica, ética y política sobre los valores ligados a este modelo y a nuestras teorías científicas en general, ya que como dijimos antes, ello puede promover la naturalización o el fortalecimiento de determinados supuestos sobre la vida y la naturaleza humana.

En segundo lugar, esta perspectiva desmonta la idea de que el conocimiento científico por sí mismo pueda fundamentar todas nuestras prácticas y creencias. Una de las actitudes que subyacía en el modelo nuclear de la herencia intentaba reducirla la vida y la naturaleza humana a las unidades de la vida que determinan a los organismos, dentro de una falsa dicotomía de naturaleza y cultura, entendida como permanente y cambiante. La visión reduccionista de la naturaleza sugería vincularse con una sociedad atomizada, donde lo primero es el individuo y éste constituye las características de lo social. Si bien creo que la reducción resulta ética y políticamente indeseable, tampoco se trata de concebir nuestro particular estatus moral como algo fundamentado por tener entendimiento o lenguaje, un estatus metafísico o epistémico especial (Rorty 2004). Se trata más bien de distinguir que si la biología nos puede decir cosas muy interesantes e importantes sobre cómo funcionan nuestros cerebros y cuerpos, jamás nos podrás decir qué tipo de conducta promover o cómo queremos vivir (ibíd., p.21). Para ello requerimos de otro vocabulario.

14 Hoy esta concepción es más lejana al reduccionismo y el mecanicismo inicial debido a procesos como la activación y desactivación de proteínas, el papel del ambiente celular y extra-celular, un entramado de redes de interacción entre proteínas, RNA, DNA y otras biomoléculas que participan como un todo integrado con el entorno. 
Así, resulta útil ver la biología como una aproximación de lo que contienen nuestras teorías sobre la vida, pero es nuestra obligación asumir responsabilidad de las consecuencias inmediatas y mediatas, hoy materializadas en toda biotecnología disponible y tan polémica. Ello nos obliga a considerar si perseguimos los fines que nos promete y los valores que puede sustentar o preferimos otros. Y esa es una pregunta de carácter político que no puede ser evadida por nuestro, en términos rortianos, «compromiso con la descripción del mundo». Posicionarnos respecto de estas responsabilidades desde la biología y la filosofía de la biología, mostrar su dimensión axiológica y delimitar su papel cultural es la consecuencia de asumir la prioridad ontológica de lo social.

\section{REFERENCIAS}

ABIR-AM, Pnina. «The Discourse of Physical Power and Biological Knowledge in the 1930s: A Repraisal of the Rockefeller Foundation's 'Policy' in Molecular Biology». Social Studies of Science, 12: 341-382, 1982.

- - - «De la colaboración multidisciplinar a la objetividad transnacional: el espacio internacional, constitutivo de la biología molecular, 1930-1970», Arbor, 156(614), 111-150, 1997.

- - - «The Rockefeller Foundation and the Rise of Molecular Biology», Nature Reviews, 3, 65-70, 2001.

- - -, «Molecular Biology in the Context of British, French, and American Cultures» International Social Science Journal, 56 (168), 187-199, 2001.

BARTELS, Ditta. «The Rockefeller Foundation’s Funding Policy for Molecular Biology: Success or Failure?» Social Studies of Science, 14(2): 238-243, 1984.

- - - Atomic Theory and the Description of Nature. New York: Cambridge University Press, 1934.

CHADAREVIAN, Soraya de. Designs for Life, Cambridge: Cambridge University Press, 2002.

DEWEY, John. Logic: The Theory of Inquiry, Vol. 12, Carbondale: Illinois University Press, 1986.

DOUGLAS, H., «Rejecting the Ideal of Values-Free Science», en Value-Free Science? Ideas and Illusions, (Eds. Kincaid, H., Dupré J. \& Wylie, A.), New York: Oxford University Press, pp. 120-139, 2007.

ECHEVERRÍA, Javier. Ciencia y Valores. Barcelona: Ediciones Destino, 2002.

FAERNA, Ángel M. Introducción a la teoría pragmatista del conocimiento, Madrid: Siglo XXI, 1996. 
FALK, Raphael. «The gene- A concept in Tension» en The Concept of the Gene in Development and Evolution Historical and Epistemological Perspectives, (Eds). Beurton, P. J. Falk, R. y Rheinbergher H.J., Cambridge: Cambridge University Press, pp. 317-348, 2000.

FOX, Evelyn. «Physics and the Emergence of Molecular Biology: A History of Cognitive and Political Synergy». Journal of the History of Biology, 23 (3): 389-409, 1990.

GAUDILLIÈRE, Jean-Paul. «¿La biología molecular en la tradición francesa?: Redefiniendo tradiciones locales y patrones disciplinares», Arbor, 156 (614), 45 77, 1997.

KAY, Lily E. «Conceptual Models and Analytical Tools: The Biology of Physicist Max Delbrück». Journal of the History of Biology, 18 (2): 207-246, 1985.

- - , The Molecular Vision of Life. Caltech, the Rockefeller Foundation and the Rise of the New Biology. New York: Oxford University Press, 1993.

- - - «Rethinking Institutions: Philanthropy as an Historiographic Problem of Knowledge and Power». Minerva, 35: 283-293, 1997.

KOHLER, Robert, E. «The Management of Science: The Experience of Warren Weaver and the Rockefeller Foundation Programme in Molecular Biology». Minerva, 14 (3): 279-306, 1976.

MAYR, Ernst. The Growth of Biological Thought. Diversity Evolution, and Inheritance. Massachusetts, Harvard University Press, 1982.

LEWONTIN, Richard C. Biology as Ideology. The Doctrine of DNA. Ontario: House of Anansi Press, 1995.

OLBY, Robert. «Schrödinger's Problem: What Is Life?» Journal of the History of Biology, 4 (1): 119-148, 1971.

- - - «The Molecular Revolution in Biology», en Companion to the History of Modern Science, (Eds. Olby, R.C., Cantor, J.R.R. y Hodge M.J.S), London, Routledge, pp. 503-521, 1990.

RHEINBERGER, Hans-Jörg, «Fragments from the Perspective of Molecular Biology» en The Concept of the Gene in Development and Evolution Historical and Epistemological Perspectives, (Eds). Beurton, Peter J. et.al., Cambridge: Cambridge University Press, pp. 219-239,2000.

RHEINBERGER, Hans-Jörg, Müller-Wille, Staffan and Meunier, Robert, «Gene», The Stanford Encyclopedia of Philosophy (Spring 2015 Edition), Edward N. Zalta (ed.), $\mathrm{URL}=<\mathrm{http}: / /$ plato.stanford.edu/archives/spr2015/entries/gene/>.

RORTY, Richard. «Solidarity or Objectivity?» en Objectivity, Relativism, and Truth Philosophical Papers Vol. 1, Cambridge: Cambridge University Press, pp. 21-34, 1991. 
- - - Consecuencias del pragmatismo, Madrid; Tecnos, 1996.

———, «Philosophy-Envy», Daedalus, Fall: 18-24, 2004.

SAPP, Jan. Beyond the Gene. Cytoplasmic Inheritance and the Struggle for Authority in Genetics. New York: Oxford University Press, 1987.

SERRANO-BOSQUET, Francisco J.; CAPONI, Gustavo. «Warren Weaver y el Programa de Biología Experimental de la Fundación Rockefeller». Scientiae Studia, 12(1): 137-167, 2014.

TABERY, James, PIOTROWSKA, Monika and DARDEN, Lindley, «Molecular Biology», The Stanford Encyclopedia of Philosophy (Spring 2016), Edward N. Zalta (ed.), URL $=<$ http://plato.stanford.edu/archives/spr2016/entries/molecularbiology/>.

WEAVER, W. Weaver to Tisdale, Rockefeller Archive Center, RG3, 915, Box 1.2, February 8, 1935.

———, «Why is Science Important?» Nutrition Review, 19(3): 65-68, 1961.

_- _, «Molecular Biology: the Origin of the Term» Science, 170.581-2, 1970.

YOXEN, Edward. «Giving Life a New Meaning: The Rise of the Molecular Biology Establishment». Scientific Establishments and Hierarchies. Sociology of the Sciences, VI: 123-143, 1982.

NALliely Hernández es profesora de tiempo completo de filosofía de la ciencia y epistemología en la Universidad de Guadalajara, México. Es licenciada en física por la Universidad Nacional Autónoma de México y doctora en filosofía por la Universidad Complutense de Madrid.

Líneas de Investigación:

Filosofía de la Ciencia, Filosofía de la Física y la Biología. Relaciones entre ciencia y cultura y pragmatismo norteamericano.

Publicaciones recientes:

«Expertos en la vida pública: ¿élites independientes o investigación socializada? Una aportación al debate Lippmann-Dewey en el contexto contemporáneo», Península, 12/2 (2017) pp. 169-199

«Rorty y Fraser en torno a la distinción entre redistribución y reconocimiento: un debate abierto» Quadripartita Ratio: Revista de Retórica y Argumentación, 2/2016.

«Similitudes entre física cuántica y la psicología de Jung: el caso de la sincronicidad o de cómo fracasa una analogía» Sincronía, 70/2016

Correo electrónico:

nallie3112@hotmail.com 
